\title{
Relationship between mentalizing abilities, attachment styles, anxiety and depressive symptom levels in fibromyalgia patients
}

\author{
Leman Inanc ${ }^{1 \oplus}$, Nurdan Eren Bodur ${ }^{2 \oplus}$, Selvinaz Cinar Parlak ${ }^{3 \oplus}$, Meral Sarikaya ${ }^{3 \oplus}$, Aylin Sari ${ }^{4 \oplus}$, \\ Huseyin Gulec ${ }^{5}$, Serhat Citak ${ }^{6}$ \\ 'Mugla Sitki Kocman University, Faculty of Medicine, Department of Psychiatry, Mugla - Turkey \\ ${ }^{2}$ Independent Researcher - The Netherlands \\ ${ }^{3}$ Uskudar University, NP Istanbul Brain Hospital, Department of Psychology, Istanbul - Turkey \\ ${ }^{4}$ Erenkoy Physical Therapy and Rehabilitation Hospital, Department of Physical Medicine and Rehabilitation, Istanbul - Turkey \\ ${ }^{5}$ Erenkoy Mental and Neurological Diseases Training and Research Hospital, Adult Mental Health, Istanbul - Turkey \\ ${ }^{6}$ Istanbul Medeniyet University, Faculty of Medicine, Department of Psychiatry, Istanbul - Turkey
}

\begin{abstract}
Objective: The aim of this study is to evaluate patients with fibromyalgia in terms of mentalizing abilities and to identify the relationships between mentalization skills, attachment styles, anxiety, and depressive symptoms in these patients.

Method: The sample consisted of 30 patients diagnosed with fibromyalgia and 30 healthy volunteers. Patients with fibromyalgia and the control group were both administered the following battery of tests: Reading the Mind in the Eyes Test (RMET), Experiences in Close Relationships Questionnaire-Revised (ECR-R), Beck Anxiety Inventory (BAI), Beck Depression Inventory (BDI).

Results: Fibromyalgia group and healthy controls differed significantly in terms of total scores of the RMET. The fibromyalgia group had significantly lower scores in terms of mentalization skills compared to healthy controls. The mean anxiety and depression scores of the fibromyalgia group were higher than in the healthy controls. The mean scores of anxiety and avoidance dimensions in the fibromyalgia group were not different from healthy controls.

Conclusion: Fibromyalgia patients were found to have significantly lower mentalizing abilities compared to healthy controls. This study may provide data for clinical applications using mentalization as a tool to understand and treat the patients diagnosed with fibromyalgia more efficiently.
\end{abstract}

Keywords: Attachment, fibromyalgia, mentalizing

\section{INTRODUCTION}

Fibromyalgia is a condition characterized by widespread pain in the musculoskeletal system, seen in the age group 20-50 years. A lifetime prevalence of $0.7-3.2 \%$ has been found, and the male-to-female ratio was 1 to 4 (1). Affected patients often show mainly depressive symptoms and signs of anxiety, frequently accompanied

How to cite this article: Inanc L, Bodur NE, Cinar Parlak S, Sarikaya M, Sari A, Gulec H, Citak S. Relationship between mentalizing abilities, attachment styles, anxiety, and depressive symptom levels in fibromyalgia patients. Dusunen Adam The Journal of Psychiatry and Neurological Sciences 2019;32:113-20.

Correspondence: Leman Inanc, Mugla Sitki Kocman University, Faculty of Medicine, Department of Psychiatryi Mugla - Turkey Phone: +90252 2147515 E-mail: lemaninanc@mu.edu.tr

Received: September 11, 2018; Revised: September 21, 2018; Accepted: March 05, 2019 
by complaints such as fatigue, exhaustion, sleep disturbances, and headache (2). While a number of hypotheses have been proposed for the etiopathogenesis of fibromyalgia, this psychosomatic syndrome is still not completely understood (3).

Current research shows likely relations of the pain with communication of emotion, empathy, attachment, and rejection (4).

Study at the Paris Institute for Psychosomatics noted that persons with psychosomatic complaints showed unproductive, trenchant, and unimaginative expressions and a mechanical thinking structure. This mental state was termed operational thinking, and it signified a lack of mentalizing ability (5).

In a review analyzing the relationship between psychosomatic diseases and mentalization, Gubb (6) called the deficiency of theory of mind "speechless mind" from the perspective of the Paris School of Psychosomatics and "speaking brain" according to the views of attachment theory. Psychoanalytical studies with psychosomatic patients point to their problems with mentalization (7).

The capacity to understand that people have different wishes, beliefs, and thoughts is called theory of mind or mentalizing ability. The human mind contains mental representations of the individual's own thoughts, wishes, and behaviors, and these representations are important in order to anticipate the mental representations of other persons $(8,9)$. This is why this ability facilitates our interpersonal understanding and our social relations.

When it comes to psychopathologies of the theory of mind-related faculties, initially autism and pervasive developmental disorder would be mentioned (10). In subsequent years, a disorder of theory of mind has been referred to in a number of conditions, from autism to schizophrenia (9).

It has been pointed out that the development of mentalizing ability is based upon a healthy attachment with the caregiver. Fonagy et al. (11) stressed the particular importance of healthy attachment for the development of symbolic capacity and early mentalizing abilities. As Choi-Kain and Gunderson (12) relate, Fonagy brings together the theoretical dimension of the theory of mind concept and the clinical aspect related to the psychoanalytic concept of secure attachment. A child that develops secure attachment with the caregiver gains the ability to understand thoughts and actions first of their caregivers and later those of other people with whom they maintain close relationships. As other researchers said, opinions about the processes or feelings in that person's mind are being formulated (13). A study on the attachment styles of fibromyalgia patients found that they had a prevalence of secure attachment of $51.7 \%$ (14).

While there are studies separately analyzing mentalization, depressive symptoms, symptoms of anxiety, and attachment styles, only one study assessed these concepts jointly (15). To our knowledge, no study has assessed this topic in Turkey.

In line with this data, the present study tests the following hypotheses: Given that fibromyalgia is a psychosomatic disease, mentalizing ability in patients is worse than in the healthy group; attachment styles are related with mentalizing ability; mentalizing ability is related with the level of anxiety and depressive symptoms.

The aim of this study is to compare the theory of mind abilities of fibromyalgia patients and healthy volunteers and, as fibromyalgia is a psychosomatic disease, to assess the relation of theory of mind abilities with attachment styles and levels of anxiety and depressive symptoms in fibromyalgia patients. We anticipate that this study will contribute to a better understanding of fibromyalgia, a disease whose etiology is still not clear.

\section{METHOD}

The study was carried out with 30 consecutive fibromyalgia patients presenting to the policlinic of Erenkoy Physical Medicine and Rehabilitation Hospital with a diagnosis according to the criteria of the American College of Rheumatology (ACR) who had not received psychiatric treatment previously. In the same period of time, a healthy control group was set up, consisting of 30 volunteers from among the staff of Erenkoy Teaching and Research Hospital for Mental Health and Neurological Diseases and Erenkoy Physical Medicine and Rehabilitation Hospital.

Both patient and control group received detailed information about the study. During the clinical interviews with the patients, individuals with mental retardation, psychotic findings, or severely depressive cases with suicidal ideation were excluded. After the information procedure, participants accepting to participate signed an informed consent form and were enrolled in the study.

Patient and controls were assessed by a consultant psychiatrist through a clinical interview. Patients were enlisted consecutively from cases that were either being followed by a physiotherapist in the policlinic with a 
diagnosis of fibromyalgia or those receiving a new diagnosis. Patients referred by the specialist for physiotherapy and rehabilitation were assessed by a consultant psychiatrist. Having examined 55 patients, during the interviews 12 of them expressed the decision not to participate in the study and were thus excluded. In addition, 7 patients were excluded for filling in the scales incompletely, 2 for being illiterate, 1 for being diagnosed with depression with psychotic features during the examination, and 2 who in the assessment received a diagnosis of depressive disorder with suicidal ideation.

This study was begun after receiving approval from the ethics committee of Erenkoy Teaching and Research Hospital for Mental Health and Neurological Diseases.

\section{Measures}

Data Collection Form: This form, prepared by the researchers in view of the aim of the study, collected information about the patients' and the controls' age, educational and marital status, and employment situation.

Reading the Mind in the Eyes Test (RMET): The RMET, developed by Baron-Cohen et al. (16), consists of photos showing only the eye area of actors and actresses. Participants are asked to choose the emotion that best represents the mental state of the person in the photo.

As the selections do not only include simple emotions such as fearful, sad, or happy, but also complex feelings, the test indicates not just the recognition of emotions but rather the theory of mind ability. A validity and reliability study of the test in Turkish was done by Yildirim et al. (17). The Turkish form consists of 32 items.

Beck Depression Inventory (BDI): The BDI was designed by Beck et al. (18) to measure the severity of depression, monitor changes under treatment, and identify the disease. Specific symptoms of depression are identified and each sentence is scored between 0 and 3 points. The scale consists of 21 items. Patients are required to indicate the expressions that best express their current state, and the result is read from the total score. Intensity is interpreted as minimal (0-9), mild (10-16), moderate (17-29), and severe (30-63). A validity and reliability study for the Turkish version was done by Hisli (19).

Beck Anxiety Inventory (BAI): The BAI is a scale measuring the frequency of a person experiencing signs of anxiety. It is a self-report scale consisting of 21 items scored on a Likert-type scale between 0 and 3 points
(20). The total score shows the level of anxiety experienced by the subject. A validity and reliability study for Turkey was carried out by Ulusoy et al. (21). A score of 8-15 points is interpreted as mild anxiety, 16-25 points as moderate, and 26-36 points as severe anxiety.

Experiences in Close Relationships Questionnaire-Revised (ECR-R): The ECR-R consists of 36 items, of which 18 measure the dimension of anxiety and 18 the dimension of avoidance (22). Participants are asked to rate on a seven-point scale to what degree the statements reflect their emotion and thoughts in romantic relationships ( $1=$ strongly disagree, $7=$ strongly agree). Adding up the scores for the subscales measuring anxiety and avoidance, anxiety and avoidance scores are calculated.

Items $4,8,16,17,18,20,21,22,24,26,30,32,34$ and 36 are reverse-scored. Mean values of odd-numbered items are used to calculate the anxiety score, while the average of the even-numbered item scores produces the avoidance score. A validity and reliability study for Turkey was done by Selcuk et al. (23).

\section{Statistical Analysis}

Statistical analyses in this study were performed using SPSS (Statistical Package for Social Sciences) version 20.0. In the comparison between groups, $\chi^{2}$ test has been used for categorical variables and t-test for numerical values. Values with $\mathrm{p}<0.05$ have been accepted as statistically significant. To establish relationships between two variables, correlation techniques have been used. As the sample size was $\geq 30$, normal distribution was accepted and Student t-test used (24). For normally distributed continuous variables, Pearson correlation test was used.

\section{RESULTS}

A comparison of the groups' demographic and some of their clinical characteristics is shown in Table 1. The average age of the fibromyalgia group was $41.06 \pm 10.19$ years, while that of the healthy controls was $36.7 \pm 8.46$ years. The difference in average age between the groups was not significant $(\mathrm{t}[58]=-1.805, \mathrm{p}=0.076)$ (Table 1$)$.

Of the fibromyalgia patients, $60 \%$ had completed primary school, $33.3 \%$ high school, and $6.6 \%$ tertiary education. Of the healthy controls, $3.3 \%$ were literate, $40 \%$ had completed primary school, $43.3 \%$ high school, and $13.3 \%$ tertiary education. The difference in educational status between the groups was not statistically significant $\left(\chi^{2}=3.258, \mathrm{df}=3, \mathrm{p}=0.354\right.$, $\mathrm{p}>0.05$ ) (Table 1). 
Table 1: Comparison of demographic and clinical characteristics between groups

\begin{tabular}{|c|c|c|c|c|c|c|c|}
\hline & \multicolumn{2}{|c|}{$\begin{array}{c}\text { Patients } \\
n=30\end{array}$} & \multicolumn{2}{|c|}{$\begin{array}{c}\text { Controls } \\
n=30\end{array}$} & \multirow[b]{2}{*}{ df } & \multirow[b]{2}{*}{$\chi^{2}$} & \multirow[b]{2}{*}{$\mathbf{p}$} \\
\hline & $\mathbf{n}$ & $\%$ & $\mathbf{n}$ & $\%$ & & & \\
\hline Level of education & & & & & 3 & 3.258 & 0.354 \\
\hline Literate & 0 & & 1 & 3.3 & & & \\
\hline Primary school & 18 & 60.0 & 12 & 40.0 & & & \\
\hline High school & 10 & 33.3 & 13 & 43.3 & & & \\
\hline Tertiary education & 2 & 6.6 & 4 & 13.3 & & & \\
\hline Employment status & & & & & 1 & 0.606 & 0.436 \\
\hline Working & 12 & 40.0 & 15 & 50.0 & & & \\
\hline Not working & 18 & 60.0 & 15 & 50.0 & & & \\
\hline Marital status & & & & & 3 & 6.778 & 0.079 \\
\hline Single & 2 & 6.6 & 7 & 23.3 & & & \\
\hline Married & 22 & 73.3 & 22 & 73.3 & & & \\
\hline Widowed & 3 & 10.0 & 0 & 0 & & & \\
\hline Divorced & 3 & 10.0 & 1 & 3.3 & & & \\
\hline Age (Mean \pm SD) & 41.06 & 10.19 & 36.7 & 8.46 & 58 & $t=-1.805$ & 0.076 \\
\hline
\end{tabular}

*t: Student t-test, $\chi^{2}$ : Chi-square test, SD: Standard deviation, df: Degrees of freedom

Table 2: Comparison of RMET, BAI, BDI scores and ECR-R subscale mean scores between groups

\begin{tabular}{lcccccccc} 
& \multicolumn{2}{c}{ Fibromyalgia } & \multicolumn{2}{c}{ Healthy controls } & & & \\
\cline { 2 - 5 } & Mean & SD & Mean & SD & & df & t & p \\
\hline RMET & 20.37 & 4.47 & 22.67 & 4.01 & & 58 & 2.096 & 0.040 \\
BAI & 16.33 & 7.80 & 4.40 & 2.54 & & 58 & -7.971 & $<0.001$ \\
BDI & 13.83 & 7.52 & 3.77 & 2.46 & & 58 & -6.972 & $<0.001$ \\
ECR-R anxiety & 60.47 & 17.24 & 50.93 & 22.55 & & 58 & -1.840 & 0.071 \\
ECR-R avoidance & 53.73 & 24.60 & 45.13 & 21.20 & & 58 & -1.450 & 0.152
\end{tabular}

t: Student t-test, df: Degrees of freedom, RMET: Reading the Mind in the Eyes Test, ECR-R: Experiences in Close Relationships Questionnaire - Revised, BAl: Beck Anxiety Inventory, BDI: Beck Depression Inventory

Regarding their employment status, in the fibromyalgia group $40 \%$ and in the control group 50\% were actively working. In the patient group, $60 \%$ were not working, while in the control group, that ratio was $50 \%$. This difference was not statistically significant $\left(\chi^{2}=0.606, \mathrm{df}=1, \mathrm{p}=0.436\right)$ (Table 1$)$.

Looking at the marital status, $73.3 \%$ of the individuals in the fibromyalgia group were married, $6.6 \%$ single, $10.0 \%$ widowed, and $10.0 \%$ divorced. In the control group, $23.3 \%$ were single, $73.3 \%$ married, and $3.3 \%$ divorced. The difference between the groups was not statistically significant $\left(\chi^{2}=6.778, \mathrm{df}=3, \mathrm{p}=0.079\right)$ (Table 1).

There was a statistically significant difference between the groups' total RMET scores $(\mathrm{t}[58]=2.096, \mathrm{p}=0.040$ ). The total RMET score in the fibromyalgia group was significantly lower than in the control group. The anxiety scores were significantly higher in the fibromyalgia group $(\mathrm{t}[58]=-7.971, \mathrm{p}<0.001)$. The total BDI scores were significantly lower in the fibromyalgia group ( $t[58]=-$ $6.972, \mathrm{p}<0.001)$. The mean scores for the anxiety and avoidance subscales of ECR-R in the fibromyalgia group were higher than in the healthy controls $(\mathrm{t}[58]=-1.840$, $\mathrm{p}=0.071 ; \mathrm{t}[58]=-1.450, \mathrm{p}=0.152)$ (Table 2).

In the fibromyalgia group, a correlation between the total RMET score and the total BAI score was found $(\mathrm{r}=0.455, \mathrm{p}=0.012)$. No correlation was detected between total RMET score and total BDI score and ECR-R anxiety and avoidance subscales. A correlation was found between the ECR-R anxiety subscale score and the ECR-R avoidance subscale mean score ( $\mathrm{r}=0.504$, $\mathrm{p}=0.005$ ). There was a positive correlation between mean BAI scores and mean BDI scores $(r=0.383$, $\mathrm{p}=0.037)$ (Table 3). 
Table 3: Relation between the levels of anxiety and avoidance in close relationships, levels of anxiety and depressive symptoms, and theory of mind abilities in fibromyalgia patients

\begin{tabular}{lcccccccc} 
& \multicolumn{2}{c}{ RMET } & \multicolumn{2}{c}{ ECR-R anxiety } & \multicolumn{2}{c}{ ECR-R avoidance } & \multicolumn{2}{c}{ BDI } \\
\cline { 2 - 9 } & $\mathbf{r}$ & $\mathbf{p}$ & $\mathbf{r}$ & $\mathbf{p}$ & $\mathbf{r}$ & $\mathbf{p}$ & $\mathbf{r}$ & $\mathbf{p}$ \\
\hline ECR-R anxiety & 0.005 & 0.978 & & & & & & \\
ECR-R avoidance & -0.106 & 0.575 & 0.504 & 0.005 & & & & \\
BDI & 0.067 & 0.723 & 0.274 & 0.143 & 0.108 & 0.569 & & \\
BAI & 0.455 & 0.012 & 0.343 & 0.063 & 0.272 & 0.146 & 0.383 & 0.037 \\
\hline
\end{tabular}

r: Pearson correlation coefficient, RMET: Reading the Mind in the Eyes Test, ECR-R: Experiences in Close Relationships Questionnaire - Revised, BAI: Beck Anxiety Inventory, BDI: Beck Depression Inventory

Table 4: Assessment of variables predicting total RMET scores in fibromyalgia patients by simple linear regression analysis

\begin{tabular}{lccccc} 
Total RMET score & B & Standard error & Beta & t & p \\
\hline BAI & 0.261 & 0.097 & 0.455 & 2.703 & 0.012 \\
Constant & 16.101 & 1.743 & & 9.236 & $<0.001$ \\
BDI & 0.040 & 0.112 & 0.067 & 0.358 & 0.723 \\
Constant & 19.811 & 1.761 & & 11.250 & $<0.001$ \\
ECR-R avoidance & -0.019 & 0.034 & -0.229 & -0.567 & 0.575 \\
Constant & 21.408 & 2.015 & & 10.627 & $<0.001$ \\
ECR-R anxiety & 0.001 & 0.049 & 0.005 & 0.028 & 0.978 \\
Constant & 20.283 & 3.082 & & 6.582 & $<0.001$ \\
\hline
\end{tabular}

RMET: Reading the Mind in the Eyes Test, ECR-R: Experiences in Close Relationships Questionnaire - Revised, BAl: Beck Anxiety Inventory, $\mathrm{BDI}$ : Beck Depression Inventory, Beta: Regression coefficient. Constant: Constant in the regression formula, B: Weight coefficient, t: t-test

Simple linear regression analysis was applied to establish if total BAI score, total BDI score, and mean scores for the ECR-R avoidance and anxiety subscales had predictive value for the total RMET score (Table 4). Using the total RMET score as the dependent variable, total BAI score, total BDI score, total score for the ECR-R anxiety subscale, and total score for the ECR-R avoidance subscale were included as independent variables. The results of simple linear regression analysis showed that of all these variables, only the total BAI score was predictive for the total RMET score.

\section{DISCUSSION}

In accordance with our hypothesis, we found fibromyalgia patients to have worse mentalizing abilities than healthy controls. In the literature, 2 studies analyzing theory of mind abilities in fibromyalgia patients were found. In a study with 40 patients and 41 healthy controls, it was established that the mentalizing abilities of fibromyalgia patients were less adequate than those of healthy controls. This study, which also assessed depressive and anxiety symptoms, found that patients scored higher than controls on the Hospital
Anxiety and Depression Scale (15). Another study assessed mentalization ability with RMET. No significant difference was found between fibromyalgia patients and healthy controls (25). This study had not evaluated the level of anxiety and depressive symptoms. In the literature, it has also been pointed out that fibromyalgia patients are finding it difficult to express their feelings, exhibiting alexithymic traits (26).

Similarly, it has been found that chronic fatigue syndrome patients experience difficulties in expressing their own feeling and understanding other people's emotions by looking at their facial expressions (27). In complex regional pain syndrome, which is a condition accompanied by chronic pain similar to that in fibromyalgia, patients were also found to have lower theory of mind abilities than controls (28). Our results are consistent with the literature assessing mentalization abilities in pain patients.

A review article examining 31 studies, while finding contradictory results for the correlation between depression and theory of mind, showed that mentalizing ability was mainly affected only during episodes of acute depression (29). A deterioration of theory of mind abilities was found in depressive disorder with psychotic characteristics (30) and in 
severe depressive disorder with a history of previous suicide attempt (31). In euthymic periods of depressive disorder, patients' theory of mind abilities have been found identical to those of healthy controls (32). Our study found no correlation between RMET scores and depression scores. Several studies found the levels of anxiety and depressive symptoms in fibromyalgia patients higher than in controls $(33,34)$. In our study, anxiety and depressive symptom levels were higher than in healthy controls, but we did not find a correlation between mentalization ability and level of depressive symptoms. A reason for this observation may be the fact that we excluded patients with suicidal ideation and severe depression with psychotic characteristics from our study.

RMET is used to study theory of mind abilities in anxiety disorder. One study using RMET showed that severe physical anxiety in patients with panic disorder negatively affects the subject's mentalizing ability (35). Our study found a correlation between the total RMET score and the total BAI score, which may be a result of a severe physical anxiety in fibromyalgia patients.

A study investigating the correlation between pain and attachment concluded that avoidant, fearful, or disorganized attachment types with a lack of trust in the caregiver might be a risk factor for pain. It has been stated that insecure attachment is correlated with severe pain and a weak capacity of adaptation, while at the same time being a factor that may prolong, trigger, and exacerbate pain (4). A study with 146 fibromyalgia patients and 122 healthy controls found that fibromyalgia patients showed a higher ratio of insecure attachment styles compared to controls (36). In the literature, there are also studies identifying fibromyalgia patients with a secure attachment. Examining the attachment styles of 29 fibromyalgia patients, secure attachment was identified (14). Another study comparing the attachment styles of fibromyalgia patients and healthy controls found no difference between the two groups (37). Our results are in line with some part of the literature but not with some other. We found the ECR-R anxiety and avoidant attachment subscale mean scores in the fibromyalgia group different from those in the controls. A study comparing fibromyalgia patients and healthy controls found that avoidant attachment was significantly higher in fibromyalgia patients and in the relation between attachment and mentalization, stress played an intermediary role (25). The same study, assessing patients according to the severity of their disease, found a correlation between avoidant attachment and disease severity. As we did not assess the severity of fibromyalgia in our study, we do not know the severity of the disease. This correlation could be investigated in a study with a larger sample.

When comparing patients with social anxiety disorder according to attachment styles, it was found that scores for anxious and avoidant attachment scores were higher than in healthy controls. No correlation was found between ECR-R and RMET scores (38). Similarly, in our study mean ECR-R scores were not correlated with RMET scores.

The fact that our study did not found a correlation between theory of mind abilities and attachment in fibromyalgia patients might be related to the scale we used or to the limited size of our sample. It would be useful to assess this issue in studies with larger samples, using a different scale assessing mentalization abilities such as first-order false belief, irony comprehension, second-order false belief, metaphor comprehension, or faux pas individually.

As fibromyalgia often goes along with additional psychosomatic disorders, a statistical analysis of the correlation between the presence of psychosomatic comorbidities and mentalizing ability might be useful. In addition to understanding facial expression, in mentalization other communication pathways in social life such as body language, mimic, gestures, and tone of voice are also important (39). Thus we may assume that assessing mentalization with certain methods that include these communication pathways could be important. Though the transmission of emotions through facial expressions is universal, in different cultures other forms of sometimes verbal, sometimes non-verbal communication gains dominance. Thus it may be important to assess mentalizing ability with culture-specific instruments.

There are some limitations of this study, such as the small sample size. Furthermore, we did not use an additional scale assessing elements of mentalization such as false belief, faux pas, or metaphor. In addition, we did not use a structured interview instrument, and we did not investigate the duration and severity of fibromyalgia.

To conclude, the mentalization ability in fibromyalgia patients was found significantly lower than in controls. On the other hand, no correlation was found between mentalizing ability and attachment styles. In addition to backing up these findings with studies using a larger sample, it will also be useful to look at this correlation with psychosomatic diagnoses 
other than fibromyalgia. This study highlights the importance to assess mentalization processes in clinical practice in order to understand fibromyalgia patients better. The correlation between mentalization abilities and fibromyalgia disorder can provide us with ample data about this disease.

\begin{tabular}{|c|c|c|}
\hline \multicolumn{2}{|c|}{ Contribution Categories } & Author Initials \\
\hline \multirow{3}{*}{ Category 1} & Concept/Design & N.E.B., L.İ. \\
\hline & Data acquisition & L.I., S.Ç.P., M.S., A.S. \\
\hline & Data analysis/Interpretation & H.G., N.E.B., L.I. \\
\hline \multirow{2}{*}{ Category 2} & Drafting manuscript & L.í. \\
\hline & Critical revision of manuscript & N.E.B., S.Ç., L.I. \\
\hline Category 3 & Final approval and accountability & $\begin{array}{l}\text { L.I., N.E.B., S.Ç.P., M.S., } \\
\text { A.S., H.G., S.Ç. }\end{array}$ \\
\hline \multirow{2}{*}{ Other } & Technical or material support & $\mathrm{N} / \mathrm{A}$ \\
\hline & Supervision & $\mathrm{N} / \mathrm{A}$ \\
\hline
\end{tabular}

Ethics Committee Approval: The study was approved by the Local Ethics Committee.

Informed Consent: Written informed consent was obtained from the patients.

Peer-review: Externally peer-reviewed.

Conflict of Interest: The authors declared no conflicts of interest.

Financial Disclosure: The authors declared no financial support.

\section{REFERENCES}

1. Kaplan HI. History of psychosomatic medicine: emostions and cellular tissue: In Kaplan MD, Sadock BJ (editors). Comprehensive Textbook of Psychiatry. Aydin H, Bozkurt A (Translation Editors) Eighth ed., Ankara: Gunes Basimevi Ltd. Sti., 2007, 2105-2112. (Turkish)

2. McBeth J, Silman AJ. The role of psychiatric disorders in fibromyalgia. Curr Rheumatol Rep 2001; 3:157-164.

3. Gur A. Etiopathogenesis in fibromyalgia. Turkish Journal of Physical Medicine and Rehabilitation 2008; 54(Suppl.1):4-11. (Turkish)

4. Lumley MA, Cohen JL, Borszcz GS, Cano A, Radcliffe AM, Porter LS, Schubiner H, Keefe FJ. Pain and emotion: a biopsychosocial review of recent research. J Clin Psychol 2011; 67:942-968.

5. Parman T. History of psychosomatics and children's psychosomatics. Psikanaliz Yazilari 2005; 11:16-17. (Turkish)

6. Gubb K. Psychosomatics today: a review of contemporary theory and practice. Psychoanal Rev 2013; 100:103-142.

7. Pedrosa Gil F, Weigl M, Wessels T, Irnich D, Baumüller E, Winkelmann A. Parental bonding and alexithymia in adults with fibromyalgia. Psychosomatics 2008; 49:115-122.

8. Abu-Akel A, Shamay-Tsoory S. Neuroanatomical and neurochemical bases of theory of mind. Neuropsychologia 2011; 49:2971-2984.
9. Sayin A, Candansayar S. Theory of mind in schizophrenia. New Symposium 2008; 46:74-80. (Turkish)

10. Baron-Cohen S, Leslie AM, Frith U. Does the autistic child have a "theory of mind"? Cognition 1985; 21:37-46.

11. Fonagy P, Gergely G, Jurist EL, Target M. Affect Regulation, Mentalization, and the Development of the Self. New York: Other Press, 2002, 55.

12. Choi-Kain LW, Gunderson JG. Mentalization: ontogeny, assessment, and application in the treatment of borderline personality disorder. Am J Psychiatry 2008; 165:1127-1135.

13. Ozturk MO, Ulusahin A. Mental Health and Disorders. Eleventh ed., Ankara: Tuna Matbaacilik San. ve Tic. A.S., 2008; 610-612. (Turkish)

14. Govender C, Cassimjee N, Schoeman J, Meyer H. Psychological characteristics of FMS patients. Scand J Caring Sci 2009; 23:76-83.

15. Di Tella M, Castelli L, Colonna F, Fusaro E, Torta R, Ardito $\mathrm{RB}$, Adenzato M. Theory of mind and emotional functioning in fibromyalgia syndrome: an investigation of the relationship between social cognition and executive function. PloS One 2015; 10:e0116542.

16. Baron-Cohen S, Wheelwright S, Hill J, Raste Y, Plumb I. The "Reading the Mind in the Eyes Test" revised version: a study with normal adults, and adults with Asperger syndrome or highfunctioning autism. J Child Psychol Psychiatry 2001; 42:241-251.

17. Yildirim EA, Kasar M, Guduk M, Ates E, Kucukparlak I, Ozalmete EO. Investigation of the reliability of the "Reading the Mind in the Eyes Test" in a Turkish Population. Turk Psikiyatri Derg 2011; 22:177-186. (Turkish)

18. Beck AT, Ward CH, Mendelson M, Mock J, Erbaugh J. An inventory for measuring depression. Arch Gen Psychiatry 1961; 4:561-571.

19. Hisli N. Reliability and validity of the Beck Depression Inventory in university students. Psikoloji Dergisi 1989; 7:3-13. (Turkish)

20. Beck AT, Epstein N, Brown G, Steer RA. An inventory for measuring clinical anxiety: psychometric properties. J Consult Clin Psychol 1988; 56:893-897.

21. Ulusoy M, Sahin NH, Erkmen H. Turkish version of the beck anxiety inventory: psychometric properties. J Cogn Psychother 1998; 12:163-172.

22. Fraley RC, Waller NG, Brennan KA. An item response theory analysis of self-report measures of adult attachment. J Pers Soc Psychol 2000; 78:350-365.

23. Selcuk E, Gunaydin G, Sumer N, Uysal A. A new scale developed to measure adult attachment dimensions: Experiences in Close Relationships-Revised (ECR-R) - Psychometric Evaluation in a Turkish Sample. Turkish Psychological Articles 2005; 8:1-11. (Turkish)

24. Disci R. Basic and Clinical Biostatistics. Revised Second Ed., Istanbul: Istanbul Tip Kitabevi, 2012, 103. (Turkish)

25. Oracz K. The relationship between adult attachment style and fibromyalgia as mediated by social cognition. Doctoral Thesis in Clinical Psychology, Canterbury Christ Church University, 2014. 
26. Pedrosa Gil F, Weigl M, Wessels T, Irnich D, Baumuller E, Winkelmann A. Parental bonding and alexithymia in adults with fibromyalgia. Psychosomatics 2008; 49:115-122.

27. Oldershaw A, Hambrook D, Rimes KA, Tchanturia K, Treasure J, Richards S, Schmidt U, Chalder T. Emotion recognition and emotional theory of mind in chronic fatigue syndrome. Psychol Health 2011; 26:989-1005.

28. Shin NY, Kang DH, Jang JH, Park SY, Hwang JY, Kim SN, Byun MS, Park HY, Kim YC. Impaired recognition of social emotion in patients with complex regional pain syndrome. J Pain 2013; 14:1304-1309.

29. Berecz H, Tenyi T, Herold R. Theory of mind in depressive disorders: a review of the literature. Psychopathology 2016; 49:125-134.

30. Cao Y, Zhao QD, Hu LJ, Sun ZQ, Sun SP, Yun WW, Yuan YG. Theory of mind deficits in patients with esophageal cancer combined with depression. World J Gastroenterol 2013; 19:29692973.

31. Szanto K, Dombrovski AY, Sahakian BJ, Mulsant BH, Houck PR, Reynolds CF, Clark L. Social emotion recognition, social functioning, and attempted suicide in late-life depression. Am J Geriatr Psychiatry 2012; 20:257-265.

32. Kerr N, Dunbar RI, Bentall RP. Theory of mind deficits in bipolar affective disorder. J Affect Disord 2003; 73:253-259.
33. Ucar M, Sarp U, Karaaslan O, Gul AI, Tanik N, Arik HO. Health anxiety and depression in patients with fibromyalgia syndrome. J Int Med Res 2015; 43:679-685.

34. Sener U, Ucok K, Ulasli AM, Genc A, Karabacak H, Coban NF, Simsek H, Cevik H. Evaluation of health-related physical fitness parameters and association analysis with depression, anxiety, and quality of life in patients with fibromyalgia. Int J Rheum Dis 2016; 19:763-772.

35. Cicek F. Attachment styles and theory of mind processes in patients with panic disorder. Specialization Thesis, Bakirkoy Hospital for Mental Health and Neurological Diseases, Istanbul, 2012. (Turkish)

36. Penacoba C, Perez-Calvo S, Blanco S, Sanroman L. Attachment styles, pain intensity and emotional variables in women with fibromyalgia. Scand J Caring Sci 2018; 32:535-544.

37. Silva PLPDS. The role of adult attachment styles in fibromyalgia. Master's Thesis, University of Coimbra Faculty of Medicine, 2011.

38. Kucukparlak I. Theory of mind and attachment processes in cases with social anxiety disorder. Specialization Thesis, Bakirkoy Hospital for Mental Health and Neurological Diseases, Istanbul, 2011. (Turkish)

39. Burgoon JK, Guerrero LK, Floyd K. Nonverbal Communication. Abingdon: Routledge, 2016, 112. 